\title{
RelB regulates manganese superoxide dismutase gene and resistance to ionizing radiation of prostate cancer cells
}

\author{
Aaron K. Holley, Yong Xu, Daret K. St. Clair, and William H. St. Clair \\ Graduate Center for Toxicology, University of Kentucky, Lexington, Kentucky
}

\begin{abstract}
Radiation therapy is in the front line for treatment of localized prostate cancer. However, a significant percentage of patients have radiation-resistant disease. The NF-кB pathway is an important factor for radiation resistance, and the classical (canonical) pathway is thought to confer protection of prostate cancer cells from ionizing radiation. Recently, the alternative (noncanonical) pathway, which is involved in prostate cancer aggressiveness, has also been shown to be important for radiation resistance in prostate cancer. The alternative NF- $\kappa B$ pathway component RelB protects prostate cancer cells from the detrimental effects of ionizing radiation, in part, by stimulating expression of the mitochondria-localized antioxidant enzyme manganese superoxide dismutase (MnSOD). Blocking RelB activation suppresses MnSOD expression and sensitizes prostate cancer cells to radiation. These results suggest that RelB-mediated modulation of the antioxidant capacity of prostate cancer cells is an important mechanism of radiation resistance. Therefore, targeting RelB activation may prove to be a valuable weapon in the oncologist's arsenal to defeat aggressive and radiation-resistant prostate cancer.
\end{abstract}

\section{Keywords}

RelB; manganese superoxide dismutase; prostate cancer; radiation resistance

\section{Introduction}

In the United States, prostate cancer is ranked first in new cancer cases and second in cancer-related deaths (behind cancer of the lung and bronchus). ${ }^{1}$ Many strategies have been devised to treat prostate cancer, including androgen ablation therapy (chemical or surgical castration), radical prostatectomy, and radiation therapy (external beam radiation therapy or interstitial brachytherapy). ${ }^{2}$

A serious obstacle in prostate cancer treatment is the development of radiation resistance (reviewed in Ref. 3). The disease recurs in as many as 30-40\% of prostate cancer patients receiving radiation therapy. ${ }^{2}$ Many mechanisms of radiation resistance in prostate cancer have been identified. ${ }^{3}$ Ionizing radiation induces changes in steroid hormone receptor expression in both patient samples and the LNCaP human prostate cancer cell line. An increase in the expression of estrogen receptor- $\beta$ after radiation treatment is significantly associated with a decrease in recurrence-free survival. ${ }^{4}$ An increase in the ratio of bcl-2 to

(C) 2010 New York Academy of Sciences.

Address for correspondence: William H. St. Clair, University of Kentucky - Graduate Center for Toxicology, 1095 VA Drive 454, HSRB, Lexington, KY 40536. stclair@email.uky.edu.

Conflicts of interest

The authors declare no conflicts of interest. 
bax in some prostate cancer patients correlates with poor responsiveness to radiation therapy. ${ }^{5}$ In a study by Skvortsova et al., three ionizing radiation resistant (IRR) prostate cancer cell lines that were created (LNCaP-IRR, PC3-IRR, and DU145-IRR) by repetitive exposure to ionizing radiation were significantly more resistant to ionizing radiation and demonstrated increased motility compared to parental cell lines. This radiation resistance correlated with up-regulation of epidermal growth factor receptor (EGFR) expression in all three radiation-resistant cell lines and expression of androgen receptor in the androgenresponsive LNCaP-IRR cell line, resulting in increased activation of phosphotidylinositol-3 kinase (PI3K) and mitogen-activated protein kinase (MAPK) signaling pathways. Activation of these signaling pathways after radiation exposure leads to increased expression of proteins involved in receptor internalization and exocytosis, cell survival, DNA repair, cell motility, signal transduction, and cell survival. ${ }^{6}$

The stress-responsive transcription factor NF- $\mathrm{kB}$ has been linked to cancer development and progression in many types of cancer by its regulation of genes involved in both cell survival and aggressiveness. ${ }^{7} \mathrm{NF}-\mathrm{\kappa B}$ activation is important for radiation resistance in many cancers, ${ }^{8,9}$ in part, by modulating the expression of genes involved in oxidative stress response, such as manganese superoxide dismutase (MnSOD). ${ }^{10}$ The role of the classical $\mathrm{NF}-\kappa \mathrm{B}$ pathway in radiation resistance of cancer cells is well characterized, but much less is known about the involvement of the alternative NF- $\mathrm{BB}$ pathway in resistance to radiation. This review focuses on the role of NF- $\kappa \mathrm{B}$ in radiation resistance in cancer, in particular, the emerging role of the alternative NF- $\mathrm{kB}$ pathway in the regulation of the antioxidant enzyme $\mathrm{MnSOD}$ and radiation resistance in prostate cancer cells. It also addresses potential treatments that target the alternative pathway to sensitize prostate cancer cells to therapeutically relevant doses of ionizing radiation.

\section{lonizing radiation and reactive oxygen species}

Reactive oxygen species (ROS) are the products of oxygen metabolism ${ }^{11}$ and are involved in a variety of cellular processes, such as signaling, ${ }^{12}$ cell adhesion, immune response, and apoptosis. ${ }^{13}$ ROS are generated from both endogenous (i.e., mitochondria ${ }^{14}$ ) and exogenous (i.e., ionizing radiation ${ }^{15}$ ) sources and include the superoxide radical $\left(\mathrm{O}_{2}{ }^{-}\right)$and hydrogen peroxide $\left(\mathrm{H}_{2} \mathrm{O}_{2}\right) .{ }^{16}$ Radiation-generated ROS are formed from either direct interactions with cellular targets or the radiolysis of water, eventually leading to DNA damage and cell death, making ionizing radiation a powerful tool for cancer treatment. ${ }^{15}$

ROS exert their effects, in part, by altering the activity of many proteins, including diverse transcription factors such as NF- $\mathrm{kB},{ }^{17}$ as well as myriad tyrosine and serine/threonine kinases ${ }^{18}$ and mitogen-activated protein kinases. ${ }^{19,20}$ While low levels of ROS are important for normal cellular function, ${ }^{16}$ abnormal ROS production is involved in several diseases, including atherosclerosis, diabetes, ${ }^{13}$ various neurological disorders, ${ }^{21}$ and cancer. ${ }^{22}$

Cells are endowed with many enzyme systems that detoxify ROS. ${ }^{23}$ Manganese superoxide dismutase (MnSOD), a key antioxidant enzyme located in the mitochondrial matrix, is essential for radiation resistance in both normal tissues and cancer cells. Sun et al. created various Chinese hamster ovarian (CHO)cell lines stably over-expressing MnSOD, copperzinc SOD (CuZnSOD), or glutathione peroxidase (GPx). MnSOD over-expression protects $\mathrm{CHO}$ cells from cell death induced by 10 Gray ionizing radiation compared to parental cells and cells over-expressing CuZnSOD and GPx. MnSOD also increases the survival fraction of $\mathrm{CHO}$ treated with various doses of ionizing radiation, suggesting that modulation of mitochondrial ROS is important for the protection of normal cells from the detrimental effects of ionizing radiation. ${ }^{24}$ Transfection of a plasmid containing the human MnSOD in 32D cl 3 mouse hematopoietic progenitor cells results in significant protection from ionizing 
radiation, and intravenous administration of the MnSOD-containing plasmid protects mice from whole body irradiation. ${ }^{25}$ In MIA PaCa-2 human pancreatic cancer ${ }^{26}$ and oral squamous carcinoma cells, ${ }^{27}$ overexpression of MnSOD results in increased cell survival and $\mathrm{G}_{2}$ cell cycle check-point accumulation in response to ionizing radiation. Irradiation of MCF-7 human breast cancer cells causes an increase in expression and enzyme activity of MnSOD. This radiation-induced increase in MnSOD results in an increase in the expression of many cell cycle regulators (p21, cyclin A, cyclin B1), transcription factors (myc) and transcriptional regulators (GADD153). ${ }^{28}$

\section{The NF-kB pathway and cancer development}

\section{The NF-kB Pathway}

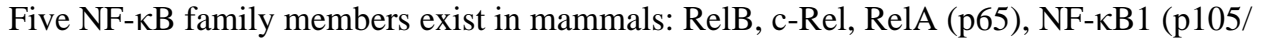

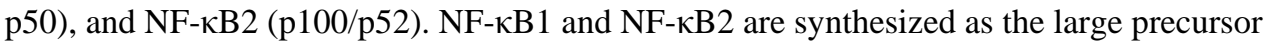
proteins p105 and p100, respectively, which are proteolytically cleaved to p50 and $\mathrm{p} 52$, which bind toDNA. AllNF- $\mathrm{kB}$ family members have a Rel-homology domain (RHD) that contains a nuclear localization sequence and is important for DNA binding, dimerization, and interaction with I $\kappa \mathrm{B}$ proteins (important inhibitors of NF- $\mathrm{KB}$ activation). NF- $\kappa B$ family members form various homodimers and heterodimers. Most combinations of dimers are transcriptionally active, but p50-p50 and p52-p52 homodimers act as transcriptional repressors. ${ }^{29}$

Under most circumstances, NF- $\mathrm{BB}$ is found in the cytoplasm and is associated with various

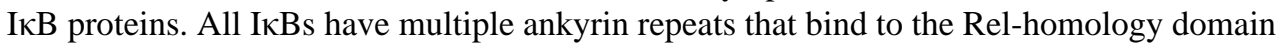
and mask the nuclear localization signal of NF- $\mathrm{KB}$, preventing translocation of NF- $\mathrm{KB}$ to the nucleus. NF-kB1(p105) and NF-kB2 (p100) also contain these ankyrin repeats. Stimulation of cells leads to phosphorylation, polyubiquitination, and proteasomal degradation of IкBs, resulting in translocation of NF- $\kappa B$ dimers to the nucleus and altered gene expression. IкBs

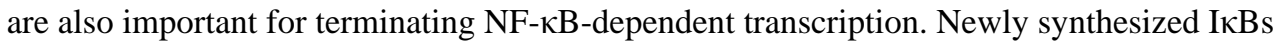
migrate to the nucleus and bind to NF- $\mathrm{kB}$, causing NF- $\mathrm{kB}$ to dissociate from DNA. This $\mathrm{I} \kappa \mathrm{B} / \mathrm{NF}-\kappa \mathrm{B}$ interaction results in export of NF- $\kappa \mathrm{B}$ to the cytoplasm due to the presence of a nuclear export signal (NES) on IкB. ${ }^{30}$

Two major NF- $\mathrm{kB}$ pathways are known to be in the cell: the classical (canonical) pathway and the alternative (non-canonical) pathway. The classical pathway involves activation of the IKB kinase (IKK) complex, which consists of the catalytic subunits IKK $\alpha$ and IKK $\beta$ and the regulatory subunit IKK $\gamma / \mathrm{NEMO}{ }^{28}$ The classical pathway depends on the kinase activity of IKK $\beta^{31}$ and requires ELKS to recruit IKB to the IKK complex, ${ }^{32}$ as well as Cdc37 and Hsp90 in the complex. ${ }^{33}$ Activation of the IKK complex results in IKK $\beta$-dependent phosphorylation of IKBs, leading to polyubiquitination and proteasomal degradation of IкB. The free NF- $\mathrm{kB}$ dimers then translocate to the nucleus, bind to DNA, and alter gene transcription. ${ }^{28}$ The alternative pathway involves activation of NF- $\mathrm{kB}$-inducing kinase $(\mathrm{NIK}),{ }^{34}$ which both phosphorylates NF-kB2 and recruits IKK $\alpha$ to $\mathrm{p} 100$ for further phosphorylation. This process stimulates polyubiquitination and partial proteolytic degradation of p100 to form $\mathrm{p} 52$, which forms a dimer with RelB and migrates to the nucleus and modifies gene expression. ${ }^{35}$

Various stimuli activate NF- $\kappa B$, resulting in the regulation of myriad NF- $\kappa$ B target genes. ${ }^{36}$ Factors that stimulate the classical pathway include different pro-inflammatory cytokines (IL-1 $\beta$ and TNF- $\alpha$ ), viruses, and Toll-like receptors, resulting in expression of many cytokines (leading to a feed-forward amplification of the signal), various chemokines, enzymes, and other genes. ${ }^{28}$ The alternative pathway is activated by a subset of tumor necrosis factor receptors (receptor activator of NF- $\mathrm{kB}$ [RANK], CD40, B cell activating 
factor belonging to the TNF family receptor [BAFFR], and lymphotoxin- $\beta$ receptor [LT $\beta R]$ ) and certain oncogenic viruses (Epstein-Barr virus and human T cell leukemia virus 1) (reviewed in Ref. 37).

The NF-kB pathway is involved in myriad cellular functions, with the classical and alternative pathways regulating different functions. The classical NF- $\kappa B$ pathway regulates the expression of genes involved in innate immunity, ${ }^{38}$ cell adhesion, stress response, and various transcription factors, ${ }^{36}$ as well as apoptosis regulators, ${ }^{39}$ growth factors, ${ }^{40}$ cell cycle regulators, ${ }^{41}$ and inflammatory cytokines. ${ }^{42}$ NF- $\mathrm{KB}$ is also involved in the regulation of cell cycle progression and apoptosis. The alternative pathway plays an important role in immune system development and maintenance by regulating lymph node formation, ${ }^{43,44}$ controlling organogenesis of the thymus, ${ }^{45}$ and promoting B-cell development and survival. ${ }^{46}$

\section{NF-kB and cancer development}

NF- $\kappa B$ plays an important role in cancer development, with many types of cancer demonstrating aberrant activation of NF- $\kappa B$ (reviewed in Ref. 7). NF- $\kappa B$ regulates the expression of many anti-apoptotic genes that suppress apoptosis in cancer cells, including IAP1, IAP-2, XIAP, cFLIP, and Bclx $\mathrm{L}_{\mathrm{L}}$ NF- $\mathrm{KB}$ also regulates cell cycle progression by stimulating the expression of various cyclins (D1, D2, D3, and E), and c-myc. ${ }^{7} \mathrm{NF}-\mathrm{\kappa B}$ can also stimulate invasion and angiogenesis by regulating the expression of different matrix metalloproteinases (MMP-2, MMP-9) ${ }^{47}$ and angiogenic factors like IL- ${ }^{42}$ and vascular endothelial growth factor. ${ }^{40}$

NF- $\kappa \mathrm{B}$ has been implicated in prostate cancer development and progression. Using an autochthonous transgenic adenocarcinoma of the mouse prostate (TRAMP) model, Shukla $e t$ $a l$. found an increase over time in both prostate volume and progression of prostate cancer in TRAMP mice compared to non-transgenic littermates, correlating with an increase in NF- $\kappa B$ nuclear localization and DNA binding activity (p65/p50). Increase in PI3 kinase activation and PTEN expression were also observed in prostate cancer progression in TRAMP mice compared to non-transgenic controls. The increase in activities of both NF- $\kappa \mathrm{B}$ and PI3 kinase are associated with increases in several proteins linked to NF- $\mathrm{kB}$-mediated cancer development (cyclin D1, bcl-2, MMP-9, and VEGF). ${ }^{48}$ In a study comparing various prostate cancer cell lines with different levels of androgen receptor expression, cell lines that are negative for androgen receptor showed the highest constitutive NF- $\mathrm{kB}$ DNA binding activity compared to cell lines that express androgen receptor. ${ }^{49}$ Zerbini et al. found that increased expression of interleukin (IL)-6 in the androgen insensitive PC-3 and DU145 prostate cancer cells is due to constitutive activation of both the classical NF- $\kappa B$ (p50/p65) and AP- (JunD and Fra1) family members. ${ }^{50}$

While less is known about the role of the alternative NF-кB pathway in the development and progression of cancer, recent studies have begun to shed light on the function of the alternative pathway in carcinogenesis. p52 and RelB levels are elevated in a variety of pancreatic cancer cell lines and paraffin-embedded pancreatic tumor samples. RelB and p52 localized to the nucleus are also increased and correlate with greater expression of many alternative NF-kB target genes. These results suggest that the alternative pathway is constitutively active and may be important for pancreatic cancer cell function. ${ }^{51}$ NIK is important for constitutive activation of p52/RelB in pancreatic cancer cells. Knock-down of NIK using specific siRNA results in diminished p100 processing to $\mathrm{p} 52$ and decreased translocation of $\mathrm{p} 52 /$ RelB dimers to the nucleus. ${ }^{52}$ Keats et al. have identified mutations in many regulatory genes of the alternative NF-kB pathway that result in either inactivation or activation of these regulatory genes and constitutive activation of the alternative pathway observed in multiple myeloma. ${ }^{53}$ In many breast cancer cell lines, p100 is highly expressed 
compared to human mammary epithelial cells. ${ }^{54}$ Mineva et al. found that treatment of WEHI 231 B lymphoma cells with CD40 TNF receptor ligand (CD40L) protects these cells from surface IgM-induced apoptosis by induction of de novo RelB synthesis, resulting in elevated expression of MnSOD and the anti-apoptotic protein survivin. Decreased expression of RelB by specific siRNA results in increased cell cycle arrest and enhanced IgM-stimulated apoptosis. ${ }^{55}$

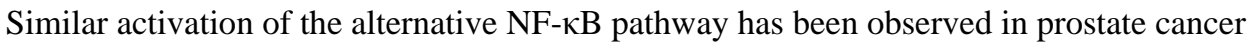
patient samples and cell lines. In prostate cancer specimens, nuclear RelB was observed in more samples (26.6\%) than RelA (15.6\%), p52 (10.7), and p50 (10.5\%). A statistically significant correlation exists between nuclear RelB and the Gleason score of the patient. ${ }^{56}$ Treatment of LNCaP human prostate cancer cells with the androgen analog R1881 results in increased cytoplasmic and nuclear accumulation of p52 through an IKK $\alpha$-dependent mechanism. Bicalutamide (an androgen receptor inhibitor), or depletion of androgen receptor using specific siRNA, significantly reduced nuclear accumulation of p52. ${ }^{57}$

\section{NF-KB and radiation resistance}

\section{NF-kB-mediated radiation resistance in normal tissues}

Ionizing radiation activatesNF- $\kappa B$ DNA binding activity ${ }^{58}$ a tissue specific manner, ${ }^{59}$ and $\mathrm{NF}-\kappa \mathrm{B}$ is important for the radioresistance of normal tissues. For example, in JB6 mouse skin epithelial cells, pretreatment with $10 \mathrm{cGy} \mathrm{X}$-ray confers radioresistance to $2 \mathrm{~Gy}$ irradiation through induction of p65 expression and DNA binding activity. p65 activation

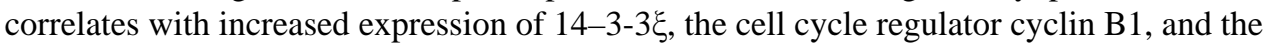
antioxidant enzyme MnSOD. Inhibition of p65 activity using the NF- $\mathrm{kB}$ inhibitor IMD-0354 results in increased radiosensitivity and decreased expression of 14-3-3 $\xi$, cyclin B1, and MnSOD. Knock-down of MnSOD using specific siRNA also results in increased radiosensitivity, suggesting that NF- $\mathrm{kB}$-regulated expression of MnSOD may be an important mechanism of induced radioresistance in normal tissues. ${ }^{60}$

\section{NF-kB confers radiation resistance to cancer cells}

$\mathrm{NF}-\kappa \mathrm{B}$ is also vital for radiation resistance in cancer cells. Treatment of KG-1 human myeloid leukemia cells with ionizing radiation results in a dose- and time-dependent increase in NF- $\kappa B$ DNA binding. Initial activation of NF- $\kappa B$ binding occurs in the absence of de novo NF- $\mathrm{kB}$ synthesis. ${ }^{58}$ Inhibition of NF-kB activity is important for sensitizing cancer cells to ionizing radiation. In Ki-Ras-transformed human prostate epithelial cells (267B1/K-ras), NF- $\kappa$ B DNA binding activity (p65/p50 and p50/p50 dimers) is much greater than in parental cells, correlating with increased resistance to ionizing radiation. Treatment with proteasome inhibitor-1 (Pro1) decreases NF- $\mathrm{KB}$ activation and confers radiosensitization to the $267 \mathrm{~B} 1 / \mathrm{K}$-ras cells. ${ }^{61}$

Activation of NF- $\mathrm{\kappa B}$ is also important in radiation resistance in prostate cancer cells. In PC-3 human prostate cancer cells, ionizing radiation stimulates NF- $\mathrm{BB}$ DNA binding activity, resulting in increased expression of the anti-apoptotic protein bcl-2. This radiationinduced, NF-kB-dependent increase in bcl-2 expression is abrogated by over-expression of the IкB super-repressor. Over-expression of the pro-apoptotic protein PAR-4 augments both radiation-induced inhibition of clonogenic survival and induction of apoptosis in PC-3 cells compared to vector controls. PAR-4 overexpression also inhibits radiation-mediated bcl-2 expression, in part, by decreasing NF- $\mathrm{BB}$ activation through inhibition of IкB $\alpha$ phosphorylation and degradation. ${ }^{62}$ In 267B1/Ki-Ras transformed human prostate epithelial cells, both constitutive and ionizing radiation-induced NF- $\mathrm{KB}$ DNA binding is much higher than in untransformed controls. Pretreatment with proteasome inhibitor-1 (Pro1) inhibits 
constitutive NF- $\mathrm{BB}$ activity and significantly increases the sensitivity of the Ki-Ras transformed cells to ionizing radiation in both time and concentration-dependent manners. ${ }^{61}$

An important mechanism of NF- $\mathrm{kB}$-mediated radiation resistance in cancer cells is the induction of MnSOD, which can affect the expression of important cell cycle and apoptosis regulators. This laboratory has identified a NF- $\kappa \mathrm{B}$ response element within an enhancer in the second intron of the MnSOD gene ${ }^{63}$ that confers NF- $\kappa B$ responsiveness of the MnSOD gene to a variety of stimuli. ${ }^{63-65}$ Nucleophosmin has subsequently been identified as an important cofactor for the NF- $\kappa \mathrm{B}$ responsiveness of MnSOD. ${ }^{66}$ Guo et al. found that MCF-7 human breast cancer cells exposed to fractionated ionizing radiation (MCF+FIR) have a 510-fold increase in MnSOD mRNA, protein, and enzyme activity after exposure to a single 5 Gy dose of ionizing radiation, and this increase in MnSOD expression correlates with increased radiation resistance in these cells. This radiation resistance was replicated by overexpressing MnSOD in MCF-7 cells (MCF+SOD). Genes regulated in both MCF+FIR and

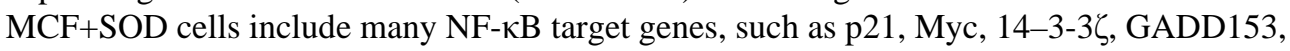
and cyclins A and B1.Over-expression of anti-sense MnSOD mRNA decreases the induction of MnSOD by ionizing radiation and results in increased radiation sensitivity. Inhibition of $\mathrm{NF}-\kappa \mathrm{B}$ activation by over-expression of a mutant I $\kappa \mathrm{B} \alpha$ inhibits MnSOD expression and decreases the expression of MnSOD-responsive genes, resulting in increased radiation sensitivity in MCF+FIR cells. Mutant I $\mathrm{BB} \alpha$ over-expression in MCF+SOD cells does not affect MnSOD-induced gene expression and radiation resistance because MnSOD expression in these cells is not controlled by NF- $\mathrm{kB}$, suggesting that NF- $\mathrm{\kappa B}$ regulation of MnSOD, which alters the expression of various pro-survival genes, is important for the radioprotective effects of NF- $\mathrm{KB}$ in cancer cells. ${ }^{67}$

\section{The alternative NF-kb pathway and radiation resistance in prostate cancer}

This laboratory has done much work to establish a better understanding of the mechanisms by which the alternative NF- $\mathrm{KB}$ pathway increases radiation resistance in prostate cancer. Josson et al. found that RelB nuclear localization is significantly higher in the aggressive PC-3 prostate cancer cell line compared to the less aggressive LNCaP cell line and correlates with increased MnSOD protein levels and enzyme activity and radioresistance in PC-3 cells ${ }^{68}$ Inhibition of RelB activity in PC-3 cells by overexpression of a dominantnegative p100 mutant or by knock-down of RelB expression by specific siRNA results in a decrease in tumor incidence and growth rate, which correlates with a decrease in IL-8 expression. Stable over-expression of RelB in LNCaP cells results in increased colony formation in soft agar compared to vector control, concomitant with an increase in IL-8 expression. ${ }^{69}$ RelB is constitutively bound to the MnSOD promoter and DNA binding increases with radiation treatment in PC-3 cells, suggesting that RelB-mediated induction of MnSOD expression is a novel response to radiation treatment. Inhibition of RelB nuclear translocation by over-expression of a dominant negative p100 or diminished RelB expression using RelB-specific siRNA causes a decrease in MnSOD expression and an increase in radiation sensitivity. ${ }^{68}$ These results suggest the importance of the alternative NF- $\kappa B$ pathway in the aggressiveness of prostate cancer cells to radiation therapy.

Because the alternative NF- $\kappa$ B pathway appears to be important for radiation resistance in prostate cancer cells, targeting this pathway may prove important for sensitizing prostate cancer cells to ionizing radiation. This laboratory developed a peptide inhibitor, SN52, that selectively targets RelB. SN52 treatment prevents radiation-induced nuclear translocation of RelB in the androgen-independent, aggressive PC-3 prostate cancer cell line, without affecting RelA translocation, by blocking the interaction of RelB with the nuclear import factors importin- $1 \alpha$ and importin-1 $\beta$. Like SN50, SN52 pretreatment blocks both constitutive and radiation-stimulated expression of MnSOD expression by 6 Gy irradiation, 
indicating that both the classical and alternative pathways are important for radiationinduced expression of MnSOD. Pretreatment with SN52 $1 \mathrm{hr}$ prior to $2 \mathrm{~Gy}$ irradiation enhances the radiosensitivity of PC-3 cells with minimal toxic effects on normal human prostate epithelial cells (PrEC). The effects of SN52 on prostate cancer radiosensitization are greater than those of SN50, suggesting that the alternative NF-אB pathway may be more important in conferring resistance to ionizing radiation in prostate cancer cells. ${ }^{70}$

Activation of the vitamin $\mathrm{D}_{3}$ receptor (VDR) is another effective way to target the alternative NF- $\mathrm{kB}$ pathway for radiosensitization in prostate cancer cells. Pretreatment with $1 \alpha, 25$-dihydroxyvitamin $\mathrm{D}_{3}\left(1 \alpha, 25-(\mathrm{OH})_{2} \mathrm{D}_{3}\right)$ increases the radiosensitivity of prostate cancer cells that express VDR (LNCaP and PC-3 cells). $1 \alpha, 25-(\mathrm{OH})_{2} \mathrm{D}_{3}$ pretreatment abolishes NF-kB DNA-binding activity by suppressing the expression of RelB, leading to a decrease in the radiation-induced expression of MnSOD and a decrease in cell viability after radiation treatment. ${ }^{71}$

\section{Conclusion}

Despite improvements in treatment options, prostate cancer continues to present a challenge to the oncologist. The development of resistance of prostate cancer to radiation is a significant complication in treating this disease. While the classical NF- $\mathrm{kB}$ pathway is an established vital player in radiation resistance, the alternative NF- $\kappa B$ pathway (through RelB) has now also been identified as a significant component of this resistance. An important mechanism of radiation resistance mediated by the alternative pathway is increased expression of the antioxidant enzyme manganese superoxide dismutase (MnSOD), which may contribute to radiation resistance by modulating ionizing radiation-induced oxidative stress in prostate cancer cells. A more complete understanding of the mechanisms by which the alternative NF- $\mathrm{BB}$ pathway enhances radiation resistance in prostate cancer may lead to improved treatment methodologies for prostate cancer, particularly in advanced prostate cancer with a high level of RelB.

\section{References}

1. Jemal A, et al. Cancer Statistics, 2009. CA Cancer J. Clin. 2009; 59:225-249. [PubMed: 19474385]

2. Thompson I, et al. Guideline for the management of clinically localized prostate cancer: 2007 update. J. Urolog. 2007; 177:2106-2131.

3. FitzGerald TJ, et al. Prostate carcinoma and radiation therapy: therapeutic treatment resistance and strategies for targeted therapeutic intervention. Expert Rev. Anticancer Ther. 2008; 8:967-974. [PubMed: 18533806]

4. Torlakovic E, et al. Differential expression of steroid receptors in prostate tissues before and after radiation therapy for prostatic adenocarcinoma. Int. J. Cancer. 2005; 117:381-386. [PubMed: 15900599]

5. Mackey TJ, et al. bcl-2/bax ratio as a predictive marker for therapeutic response to radiotherapy in patients with prostate cancer. Urology. 1998; 52:1085-1090. [PubMed: 9836559]

6. Skvortsova I, et al. Intracellular signaling pathways regulating radioresistance of human prostate carcinoma cells. Proteomics. 2008; 8:4521-4533. [PubMed: 18821526]

7. Lee $\mathrm{CH}$, et al. NF- $\mathrm{kB}$ as a potential molecular target for cancer therapy. Biofactors. 2007; 29:19-35. [PubMed: 17611291]

8. Criswell $\mathrm{T}$, et al. Transcription factors activated in mammalian cells after clinically relevant doses of ionizing radiation. Oncogene. 2003; 22:5813-5827. [PubMed: 12947388]

9. Ahmed KM, Li JJ. NF-кB-mediated adaptive resistance to ionizing radiation. Free Radic. Biol.Med. 2008; 44:1-13. [PubMed: 17967430] 
10. Murley JS, et al. Delayed radioprotection by NFאB-mediated induction of Sod2 (MnSOD) in SANH tumor cells after exposure to clinically used thiol-containing drugs. Rad. Res. 2004; 162:536546.

11. Fridovich I. The biology of oxygen radicals. Science. 1978; 201:875-880. [PubMed: 210504]

12. Forman HJ, Fukuto JM, Torres M. Redox signaling: thiol chemistry defines which reactive oxygen and nitrogen species can act as second messengers. Am. J. Physiol., Cell Physiol. 2004; 287:C246-C256. [PubMed: 15238356]

13. Droge W. Free radicals in the physiological control of cell function. Physiol. Rev. 2002; 82:47-95. [PubMed: 11773609]

14. Kakkar P, Singh BK. Mitochondria: a hub of redox activities and cellular distress control. Mol. Cell. Biochem. 2007; 305:235-253. [PubMed: 17562131]

15. Mettler, FA.; Upton, AC. Medical Effects of Ionizing Radiation. Philadelphia, PA: Saunders Elsvier; 2008.

16. Halliwell, B.; Gutteridge, JMC. Free Radicals in Biology and Medicine. New York: Oxford University Press; 2007.

17. Kabe Y, et al. Redox regulation of NF-kappaB activation: distinct redox regulation between the cytoplasm and the nucleus. Antiox. Redox Signal. 2005; 7:395-403.

18. Poli G, et al. Oxidative stress and cell signaling. Curr. Med. Chem. 2004; 11:1163-1182. [PubMed: 15134513]

19. Wang X, et al. The cellular response to oxidative stress: influences of mitogen-activated protein kinase signaling pathways on cell survival. Biochem. J. 1998; 333:291-300. [PubMed: 9657968]

20. Schafer M, et al. Role of redox signaling in the autonomous proliferative response of endothelial cells to hypoxia. Circ. Res. 2003; 92:1010-1015. [PubMed: 12690038]

21. Waris G, Ahsan H. Reactive oxygen species: role in the development of cancer and various chronic conditions. J. Carcinogen. 2006; 5:14-21.

22. Gius D, Spitz DR. Redox signaling in cancer biology. Antiox. Redox Signal. 2006; 8:1249-1252.

23. Andreyev AY, Kushnareva YE, Starkov AA. Mitochondrial metabolism of reactive oxygen species. Biochem. (Moscow). 2005; 70:246-264.

24. Sun J, et al. Role of antioxidant enzymes on ionizing radiation resistance. Free Radic. Biol. Med. 1998; 24:586-593. [PubMed: 9559871]

25. Zhang X, et al. Radioprotection in vitro and in vivo by minicircle plasmid carrying the human manganese superoxide dismutase transgene. Human Gene Ther. 2008; 19:820-826. [PubMed: 18699723]

26. Fisher CJ, Goswami PC. Mitochondria-targeted antioxidant enzyme activity regulates radioresistance in human pancreatic cancer cells. Cancer Biol. Ther. 2008; 7:1271-1279. [PubMed: 18497575]

27. Kalen AL, et al. Mn-superoxide dismutase overexpression enhances $\mathrm{G}_{2}$ accumulation and radioresistance in human oral squamous carcinoma cells. Antiox. Redox Signal. 2006; 8:12731281.

28. Bonizzi G, Karin M. The two NF- $\kappa \mathrm{B}$ activation pathways and their role in innate and adaptive immunity. Trends Immunol. 2004; 25:280-288. [PubMed: 15145317]

29. Ghosh S, May MJ, Kopp EB. NF-kB and Rel proteins: evolutionarily conserved mediators of immune response. Ann. Rev. Immunol. 1998; 16:225-260. [PubMed: 9597130]

30. Karin M, Ben-Neriah Y. Phosphorylation meets ubiquitination: the control of NF- $\kappa$ B activity. Ann. Rev. Immunol. 2000; 18:621-633. [PubMed: 10837071]

31. Li Z-W, et al. The IKK $\beta$ subunit of I $\kappa \mathrm{B}$ kinase (IKK) is essential for nuclear factor $\kappa \mathrm{B}$ activation and prevention of apoptosis. J. Exp. Med. 1999; 189:1839-1845. [PubMed: 10359587]

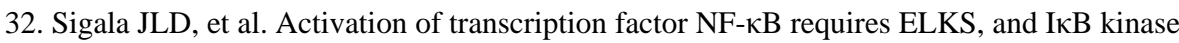
regulatory subunit. Science. 2004; 304:1963-1967. [PubMed: 15218148]

33. Chen G, Cao P, Goeddel DV. TNF-induced recruitment and activation of the IKK complex require cdc37 and hsp90. Mol. Cell. 2002; 9:401-410. [PubMed: 11864612]

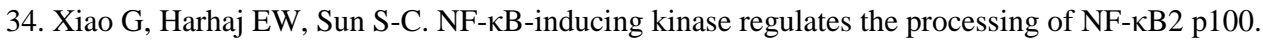
Mol. Cell. 2001; 7:401-409. [PubMed: 11239468] 
35. Senftleben U, et al. Activation by IKK $\alpha$ of a second, evolutionary conserved, NF- $\kappa \mathrm{B}$ signaling pathway. Science. 2001; 293:1495-1499. [PubMed: 11520989]

36. Pahl HL. Activators and target genes of Rel/NF-kB transcription factors. Oncogene. 1999; 18:6853-6866. [PubMed: 10602461]

37. Dejardin E. The alternative NF- $\mathrm{B}$ pathway from biochemistry to biology: pitfalls and promises for future drug development. Biochem. Pharmacol. 2006; 72:1161-1179. [PubMed: 16970925]

38. Alcamo E, et al. Targeted mutation of TNF receptor I rescues the RelA-deficient mouse and reveals a critical role for NF- $\kappa B$ in leukocyte recruitment. J. Immunol. 2001; 167:1592-1600. [PubMed: 11466381]

39. Chen C, Edelstein LC, Gelinas C. The Rel/NF- $\kappa$ B family directly activates expression of the apoptosis inhibitor Bcl-x $x_{L}$. Mol. Cell. Biol. 2000; 20:2687-2695. [PubMed: 10733571]

40. Chilov D, et al. Genomic organization of human and mouse genes for vascular endothelial growth factor C. J. Biol. Chem. 1997; 272:25176-25183. [PubMed: 9312130]

41. Guttridge DC, et al. NF- $\mathrm{BB}$ controls cell growth and differentiation through transcriptional regulation of cyclin D1. Mol. Cell. Biol. 1999; 19:5785-5799. [PubMed: 10409765]

42. Kunsch C, Rosen CA. NF- $\kappa B$ subunit-specific regulation of the interleukin-8 promoter. Mol. Cell. Biol. 1993; 13:6137-6146. [PubMed: 8413215]

43. Carragher D, et al. A stroma-derived defect in $\mathrm{NF \kappa B} 2^{-/-}$mice causes impared lymph node development and lymphocyte recruitment. J. Immunol. 2004; 173:2271-2279. [PubMed: 15294939]

44. Lo JC, et al. Coordination between NF-кB family members p50 and p52 is essential for mediating LT $\beta R$ signals in the development and organization of secondary lymphoid tissues. Blood. 2006; 107:1048-1055. [PubMed: 16195333]

45. Kinoshita D, et al. Essential role of IкB kinase $\alpha$ in the thymic organogenesis required for the establishment of self-tolerance. J. Immunol. 2006; 176:3995-4002. [PubMed: 16547234]

46. Kaisho BT, et al. IкB kinase $\alpha$ is essential for mature B cell development and function. J. Exp.Med. 2001; 193:417-426. [PubMed: 11181694]

47. Felx M, et al. Endothelin-I (ET-I) promotes MMP-2 and MMP-9 induction involving the transcription factor NF-кB in human osteosarcoma. Clin. Sci. 2006; 110:645-654. [PubMed: 16417466]

48. Shukla S, et al. Constitutive activation of PI3K-AKT and NF- $\kappa \mathrm{B}$ during prostate cancer progression in autochthonous transgenic mouse model. Prostate. 2005; 64:224-239. [PubMed: 15712212]

49. Suh J, et al. Mechanisms of constitutive NF- $\kappa$ B activation in human prostate cancer cells. Prostate. 2002; 52:183-200. [PubMed: 12111695]

50. Zerbini LF, et al. Constitutive activation of nuclear factor $\kappa \mathrm{B}$ p50/p65 and Fra- 1 and JunD is essential for deregulated interleukin 6 expression in prostate cancer. Cancer Res. 2003; 63:22062215. [PubMed: 12727841]

51. Wharry CE, et al. Constitutive non-canonical NFkB signaling in pancreatic cancer cells. Cancer Biol. Ther. 2009; 8:1567-1576. [PubMed: 19502791]

52. Nishina T, et al. NIK is involved in constitutive activation of the alternaitve NF- $\kappa B$ pathway and proliferation of pancreatic cancer cells. Biochem. Biophys. Res. Commun. 2009; 388:96-101. [PubMed: 19646419]

53. Keats JJ, et al. Promiscuous mutations activate the noncanonical NF- $\kappa B$ pathway in multiple myeloma. Cancer Cell. 2007; 12:131-144. [PubMed: 17692805]

54. Dejardin E, et al. Highly-expressed p100/p52 (NFKB2) sequesters other NF-kappa B-related proteins in the cytoplasm of human breast cancer cells. Oncogene. 1995; 11:1835-1841. [PubMed: 7478612]

55. Mineva ND, et al. CD40 ligand-mediated activation of the deNovo RelBNF- $\kappa \mathrm{B}$ synthesis pathway in transformed B cells promotes rescue from apoptosis. J. Biol. Chem. 2007; 282:17475-17485. [PubMed: 17446175]

56. Lessard L, et al. Nuclear localisation of nuclear factor-kappaB transcription factors in prostate cancer: an immunohistochemical study. Brit. J. Cancer. 2005; 93:1019-1023. [PubMed: 16205698] 
57. Lessard L, et al. NF-kB2 processing and p52 nuclear accumulation after androgenic stimulation of LNCaP prostate cancer cells. Cellular Signaling. 2007; 19:1093-1100.

58. Brach MA, et al. Ionizing radiation induces expression and binding activity of the nuclear factor кB. J. Clin. Invest. 1991; 88:691-695. [PubMed: 1864978]

59 . Zhou D, et al. A high dose of ionizing radiation induces tissue-specific activation of nuclear factorкB in vivo. Rad. Res. 1999; 151:703-709.

60. Fan M, et al. Nuclear factor- $\kappa \mathrm{B}$ and manganese superoxide dismutase mediate adaptive radioresistance in lowdose irradiated mouse skin epithelial cells. Cancer Res. 2007; 67:3220-3228. [PubMed: 17409430]

61. Kim BY, et al. NF- $\kappa$ B inhibition radiosensitizes Ki-Ras-transformed cells to ionizing radiation. Carcinogenesis. 2005; 26:1395-1403. [PubMed: 15802300]

62. Chendil D, et al. Par-4, a pro-apoptotic gene, inhibits radiation-induced NFkB activity and bcl-2 expression leading to induction of radiosensitivity in human prostate cancer cells PC-3. Cancer Biol. Ther. 2002; 1:152-160. [PubMed: 12170775]

63. $\mathrm{Xu} \mathrm{Y}$, et al. An intronic NF- $\kappa \mathrm{B}$ element is essential for induction of the human manganese superoxide dismutase gene by tumor necrosis factor- $\alpha$ and interleukin-1 $\beta$. DNA Cell Biol. 1999; 18:709-722. [PubMed: 10492402]

64. Kiningham KK, Daosukho C, St. Clair DK. IкB $\alpha$ (inhibitory $\kappa \mathrm{B} \alpha$ ) identified as labile repressor of MnSOD (manganese superoxide dismutase) expression. Biochem. J. 2004; 384:543-549. [PubMed: 15330761]

65. Kiningham KK, et al. Nuclear factor $\kappa \mathrm{B}$-dependent mechanisms coordinate the synergistic effect of PMA and cytokines on the induction of superoxide dismutase 2. Biochem. J. 2001; 353:147-156. [PubMed: 11115408]

66. Dhar SK, et al. Identification of nucleophosmin as an NF- $\mathrm{kB}$ co-activator for the induction of the human SOD2 gene. J. Biol. Chem. 2004; 279:28209-28219. [PubMed: 15087454]

67. Guo G, et al. Manganese superoxide dismutase-mediated gene expression in radiation-induced adaptive responses. Mol. Cell. Biol. 2003; 23:2362-2378. [PubMed: 12640121]

68. Josson $\mathrm{S}$, et al. RelB regulates manganese superoxide dismutase gene and resistance to ionizing radiation of prostate cancer cells. Oncogene. 2006; 25:1554-1559. [PubMed: 16261162]

69. Xu Y, et al. RelB enhances prostate cancer growth: implications for the role of the nuclear factor$\kappa \mathrm{B}$ alternative pathway in tumorigenicity. Cancer Res. 2009; 69:3267-3271. [PubMed: 19351823]

70. Xu Y, et al. SN52, a novel nuclear factor- $\kappa \mathrm{B}$ inhibitor, blocks nuclear import of RelB:p52 dimer and sensitizes prostate cancer cells to ionizing radiation. Mol. Cancer Ther. 2008; 7:2367-2376. [PubMed: 18723484]

71. Xu Y, et al. Suppression of RelB-mediated manganse superoxide dismutase expression reveals a primary mechanismC for radiosensitization effect of $1 \alpha$-25-dihydroxyvitamin $\mathrm{D}_{3}$ in prostate cancer cells. Mol. Cancer Ther. 2007; 6:2048-2056. [PubMed: 17604335] 